\title{
Divergência seletiva no estádio final de aquisição de L2: Dados sobre a construção com there em inglês ${ }^{1}$
}

\author{
Joana Teixeira \\ CLUNL, NOVA-FCSH
}

\begin{abstract}
:
This study investigates the acquisition of there-constructions (with verbs other than be) in L2 English by native speakers of European Portuguese (EP) and French. Its main purpose is to test two opposing hypotheses on the end-state of L2 acquisition at the interfaces: the Interface Hypothesis (IH) and the L1+input Hypothesis (LIH). The former proposes that internal interfaces are, generally, unproblematic at the end-state of L2 acquisition, whereas external interfaces, like the syntax-discourse interface, are areas of permanent optionality due to processing inefficiencies associated with bilingualism. The latter, in contrast, advocates that structures at external interfaces generate problems at a near-native level iff their properties are different in the L1 and the L2 and they are infrequent in the input. By administering 2 untimed drag and drop tasks, 3 speeded acceptability judgement tasks and 1 syntactic priming task to a total of 80 participants, we tested the types of overt expletives, the types of intransitive verbs and the types of discourse contexts compatible with thereconstructions in advanced and near-native English. The results confirm the IH, but suggest that the LIH is not completely wrong.
\end{abstract}

Keywords: L2 acquisition, end state, interfaces, there-construction, frequency

Palavras-chave: aquisição de L2, estado final, interfaces, construção com there, frequência

\section{Introdução}

Desde o início do século XXI, a investigação desenvolvida em aquisição de segunda língua (L2) no quadro teórico da linguística generativa tem tido como principal foco a interface entre sintaxe e outros domínios. Dois tipos de interfaces têm sido considerados: (i) as interfaces internas, i.e., as interfaces entre sintaxe e outros módulos internos à faculdade da linguagem, como o léxico, a morfologia e a semântica, e (ii) as interfaces externas, i.e., as interfaces entre sintaxe e domínios externos à faculdade da linguagem, como discurso e pragmática. De acordo com alguns autores, nomeadamente Sorace e colaboradores (Sorace, 2011b, 2012; Sorace \& Filiaci, 2006; Sorace \& Serratrice, 2009; Tsimpli \& Sorace, 2006), as propriedades que são estritamente sintáticas ou que envolvem interfaces internas não são problemáticas no estádio final de aquisição de L2, ao passo que as que envolvem interfaces externas são uma área de opcionalidade persistente, mesmo para os falantes que atingem o nível mais avançado de competência que se pode ter numa L2 - o nível quase nativo. Embora alguns estudos confirmem esta generalização, conhecida como Hipótese de Interface (HI) (Sorace, 2011b; Sorace \& Filiaci, 2006), outros têm produzido resultados que não estão em linha com as

\footnotetext{
${ }^{1}$ A investigação conducente a este artigo foi desenvolvida no âmbito do projeto de doutoramento "L2 acquisition at the interfaces: Subject-verb inversion in L2 English and its pedagogical implications", financiado pela Fundação para a Ciência e a Tecnologia (ref. ${ }^{\text {" }}$ PD/BD/52263/2013). Agradeço a Ana Madeira e a Antonella Sorace pelas suas úteis sugestões e comentários durante as fases de preparação e execução do estudo experimental apresentado neste artigo. Agradeço também a John-Sebastian Schütter pela ajuda no desenho da tarefa de priming sintático e aos revisores anónimos da Revista da Associação Portuguesa de Linguística pelos seus comentários. Por fim, queria expressar o meu agradecimento a todos os falantes nativos de francês, inglês e português europeu que participaram nas tarefas experimentais sobre construções com there em inglês.
} 
suas predições (para uma visão geral, cf. White, 2011). Por este motivo, as seguintes questões permanecem em aberto: (i) Será que as propriedades internas à gramática são invariavelmente adquiríveis em L2? (ii) Será que as propriedades que envolvem interfaces externas são necessariamente problemáticas no estádio final de aquisição de L2?

Com vista a contribuir para o debate sobre estas questões, o presente trabalho investiga a aquisição de propriedades léxico-sintáticas e sintático-discursivas da construção com there, com verbos que não be (e.g., com appear como demonstrado em (1)), por falantes avançados e quase nativos de inglês L2 que têm como línguas maternas (L1) o francês e o português europeu (PE).

$$
\begin{aligned}
& \text { [There] [appeared] [a ship] [on the horizon] (Levin, 1993: 89) } \\
& \text { EXPL V S Loc(ativo) }
\end{aligned}
$$

Este trabalho está estruturado do seguinte modo: a secção 2 sintetiza os principais resultados de estudos prévios sobre o estádio final da aquisição de L2 nas interfaces. Na secção 3, descrevemos as propriedades da inversão com expletivo em inglês, francês e PE. A secção 4 apresenta as questões de investigação, predições e metodologia do presente estudo. Na secção 5, descrevemos os seus resultados. Por fim, na secção 6, discutimos os resultados obtidos e apresentamos as conclusões do estudo.

\section{O estádio final da aquisição de $\mathrm{L} 2$ nas interfaces}

Ao longo da última década, grande parte da investigação desenvolvida em aquisição de L2 sobre interfaces linguísticas tem sido influenciada pela HI (Sorace \& Filiaci, 2006; Sorace, 2011). Segundo a atual versão desta hipótese (Sorace, 2011b, 2012), enquanto as propriedades que são estritamente sintáticas ou envolvem interfaces internas são, geralmente, adquiríveis numa L2, as que envolvem a interface entre sintaxe e domínios externos à gramática, como discurso, são uma área de opcionalidade residual ${ }^{2}$, mas permanente, no estádio final de aquisição de L2. A HI propõe que esta opcionalidade é fruto de ineficiências na integração de informação sintática com informação pragmático-discursiva no uso da língua em tempo real, as quais, por sua vez, são um efeito secundário do bilinguismo ${ }^{3}$ (Sorace, 2011a, 2011b, 2016). Mais especificamente, é defendido que o facto de o falante de L2, tal como qualquer falante com duas (ou mais) línguas ativas na mente, ter de constantemente inibir uma língua enquanto usa a outra sobrecarrega os seus recursos cognitivos e leva a que as exigências de tarefas linguísticas com elevado custo de processamento, como as que envolvem interfaces externas, excedam (inconsistentemente) os recursos cognitivos disponíveis. Esta sobrecarga leva, por isso, a ineficiências na integração de informação em tempo real, que resultam em opcionalidade na performance do falante. Segundo a HI, há mais ineficiências de integração na produção/interpretação de estruturas que envolvem a interface sintaxe-discurso/pragmática do que de estruturas que envolvem interfaces internas à gramática (e.g., sintaxe-semântica), porque a integração de informação sintática com informação proveniente de domínios externos requer mais recursos cognitivos do que a integração de informação com origem em diferentes módulos dentro da gramática (Sorace \& Serratrice, 2009). Note-se que, ao contrário do que é, por vezes, assumido, a versão atual da HI não prediz que as propriedades nas interfaces externas são impossíveis de adquirir. Esta hipótese prediz antes que, mesmo não havendo qualquer problema representacional, ineficiências de processamento relacionadas com a condição bilingue originarão opcionalidade na performance dos falantes de L2.

\footnotetext{
${ }^{2}$ Segundo Sorace (2003: 140), a opcionalidade residual é um fenómeno característico do estádio quase nativo, em que "a steady state is reached in which the target option is strongly but not categorically preferred and the nontarget option surfaces in some circumstances".

${ }^{3}$ Salvo indicação em contrário, o termo "bilingue" é usado neste artigo no sentido lato de falante com proficiência em duas ou mais línguas.
} 
A evidência que apoia a HI vem predominantemente de estudos sobre a aquisição de inversão "livre" e de sujeitos pronominais em línguas de sujeito nulo consistente, como o italiano, o espanhol e o PE. Estes estudos têm mostrado, de modo sistemático, que os falantes avançados e quase nativos destas línguas têm uma gramática de sujeito nulo, mas exibem dificuldades permanentes relativamente às condições discursivas que determinam a distribuição de ordens SV e VS e de sujeitos pronominais plenos. Este padrão de comportamento é encontrado não só em combinações de línguas em que a L1 é uma língua de sujeito obrigatório e a L2 uma língua de sujeito nulo (e.g., Belletti, Bennati, \& Sorace, 2007; Lozano, 2003, 2006; Sorace \& Filiaci, 2006), como também em pares de línguas em que a L1 e a L2 são línguas de sujeito nulo consistente (e.g., Bini, 1993; Lozano, 2008; Margaza \& Bel, 2006; Mendes \& Iribarren, 2007), o que sugere que as dificuldades na interface sintaxe-discurso não resultam (exclusivamente) da influência da L1. Além de gerarem dificuldades persistentes a falantes de L2, as propriedades sintático-discursivas dos sujeitos em línguas de sujeito nulo são problemáticas para outras populações bilingues, como crianças bilingues simultâneas (e.g., Sorace, Serratrice, Filiaci, \& Baldo, 2009) e adultos que estão numa situação de erosão linguística devido a exposição prolongada a uma L2 (e.g., Tsimpli, Sorace, Heycock, \& Filiaci, 2004). Confirmando a diferença qualitativa entre interfaces internas e externas predita pela HI, os poucos estudos em que Sorace e colegas (Serratrice, Sorace, Filiaci, \& Baldo, 2009; Sorace \& Serratrice, 2009; Sorace et al., 2009; Tsimpli \& Sorace, 2006) testaram, simultaneamente, a aquisição de propriedades nestes dois tipos de interfaces pelos mesmos grupos de falantes mostraram que, enquanto a interface externa com o discurso causa problemas persistentes, uma interface interna como a interface sintaxe-semântica não gera dificuldades a falantes quase nativos e só é problemática para crianças bilingues em idade escolar quando as suas L1s são diferentes nos aspetos relevantes. Em conjunto, estes resultados têm sido interpretados pelas proponentes da HI como evidência robusta de que (i) só as interfaces externas são invariavelmente problemáticas para falantes bilingues, em geral, e de L2, em particular, e de que (ii) tais problemas resultam de ineficiências de processamento relacionadas com a condição bilingue.

Os trabalhos que se têm debruçado sobre outras propriedades de interface e combinações de línguas têm, no entanto, produzido resultados mistos relativamente à validade da HI. De facto, embora muitos estudos confirmem que as propriedades que envolvem interfaces internas à faculdade da linguagem não são persistentemente problemáticas em L2 (e.g., Dekydtspotter, Sprouse, \& Swanson, 2001; Kraš, 2010; Slabakova, 2003), há evidência de que, em alguns casos, as interfaces sintaxe-morfologia (e.g., Hopp, 2007) e léxico-sintaxe (e.g., Kraš, 2011) podem gerar dificuldades, até mesmo a falantes quase nativos. Crucialmente, como os resultados dos estudos sobre interfaces internas não apontam para a existência de uma interface deste tipo que seja sistematicamente problemática em gramáticas quase nativas, estes estudos não colocam em causa a predição central da HI: a de que a interface sintaxe-discurso é o principal locus de opcionalidade permanente no estádio final de aquisição de L2. Mais problemático para esta hipótese é o facto de terem surgido, ao longo da última década, vários trabalhos que mostram que falantes de L2 conseguem convergir completamente com a língua alvo na aquisição de estruturas na interface sintaxe-discurso (e.g., Domínguez \& Arche, 2014; Ivanov, 2012; Slabakova, 2015). A partir do trabalho de Slabakova (2015), surgiu mesmo uma hipótese alternativa à HI, que designamos por "Hipótese L1+input" (HLI), segundo a qual as estruturas na interface sintaxe-discurso só geram problemas no estádio final de aquisição de L2 quando são diferentes na L1 e na L2 e raras no input.

Os resultados contraditórios obtidos pela investigação em aquisição de L2 na interface sintaxe-discurso suscitam a seguinte questão: Será que, afinal, só algumas estruturas nesta interface são problemáticas e não a interface como um todo? Em trabalho recente sobre a aquisição de propriedades sintático-discursivas da inversão locativa em inglês avançado e quase nativo, Teixeira (2017) sugere que o facto de os problemas na interface sintaxe-discurso serem detetados por certos estudos mas não por outros poderá dever-se a dois motivos. Um deles é o facto de a maioria dos estudos recorrer a tarefas offline, sem restrições de tempo, em 
particular a tarefas de juízos de aceitabilidade, que, como defendido por Sorace (2011b), não são as mais adequadas para se captar o tipo de opcionalidade predito pela HI, uma vez que dão aos participantes tempo ilimitado para pensarem sobre as suas respostas e acederem ao seu conhecimento (meta)linguístico. O outro motivo é que, tal como comprovado pelos resultados das experiências reportadas em Teixeira (2017), a opcionalidade na interface sintaxe-discurso não é um fenómeno categórico, mas sim gradiente: dependendo da combinação de determinados fatores, como a quantidade e distância da informação contextual a ser processada ou a distância entre L1 e L2, o grau de eficiência do falante de L2 nesta interface varia e, consequentemente, o grau de opcionalidade que exibe também. Por isso, em certos casos, a opcionalidade na interface sintaxe-discurso é detetável por tarefas offline sem restrições de tempo, ao passo que, noutros, só as tarefas mais exigentes em termos de processamento conseguem captar este fenómeno. Crucialmente, no estudo de Teixeira (2017) sobre inversão locativa em inglês L2, todos os grupos de L2 exibiram opcionalidade na interface sintaxe-discurso em, pelo menos, uma tarefa, independentemente de a sua L1 ser ou não semelhante à L2, o que está em linha com as predições da HI e infirma a HLI.

A fim de testarmos, com outro fenómeno linguístico, a HI, a HLI e a proposta de que a opcionalidade na interface sintaxe-discurso é gradiente, no presente trabalho, investigamos a aquisição da construção com there com verbos que não be por falantes avançados e quase nativos de PE L1 - inglês L2 e francês L1 - inglês L2. Este é um terreno de teste particularmente interessante para estas hipóteses por dois motivos. O primeiro é que a construção com there nos permite testar, simultaneamente, a divisão entre interfaces internas e externas predita pela HI e as predições da HI e da HLI sobre a interface sintaxe-discurso, porque é rara em inglês (Biber, Johansson, Leech, Conrad, \& Finegan, 1999), tem propriedades que envolvem interfaces internas e outras que envolvem a interface sintaxe-discurso e tem características semelhantes em inglês e francês mas não em PE (cf. secção 3). O segundo motivo é que a construção com there nunca foi investigada em inglês avançado e quase nativo, apesar de um estudo de corpus conduzido por Lozano \& Mendikoetxea $(2008,2010)$ ter revelado que, num nível intermédio alto, os aprendentes espanhóis de inglês têm um padrão de comportamento, aparentemente, inverso ao predito pela HI. Este estudo mostra que, ao contrário do que a $\mathrm{HI}$ prediria, os aprendentes espanhóis dominam a condição discursiva que determina que o sujeito lógico de ordens VS tem de ser foco em inglês, mas exibem dificuldades em relação a alguns aspetos internos à gramática. $\mathrm{O}$ mais problemático parece ser o mapeamento léxico-sintático que determina a agramaticalidade do expletivo it na posição canónica de sujeito de estruturas de inversão $(41.4 \%$ das ordens VS no corpus tinham o tipo de estrutura em (2)). Apesar de sugestivos, estes resultados não nos permitem retirar conclusões sobre a validade da HI, por um lado, porque é possível que os aprendentes testados ultrapassem os seus problemas gramaticais em níveis mais avançados e, por outro, porque este estudo apenas analisa o comportamento dos aprendentes em relação a uma das várias condições discursivas a que a construção com there está sujeita em inglês. Além disso, o facto de os dados de Lozano \& Mendikoetxea provirem de um corpus de textos escritos também poderá explicar os resultados divergentes. É, assim, necessária mais investigação.

(2) $\quad *$ it-V-S: *In the name of religion it had occurred many important events, [...].

(Lozano \& Mendikoetxea, 2010: 486)

\section{Inversão com sujeito expletivo em inglês, francês e PE}

Em inglês, existem dois tipos de construção de inversão sujeito-verbo com o expletivo there: (i) a construção existencial com there, que ocorre com o verbo be e é frequente em inglês (e.g., "there is a book on the table"), e (ii) a construção apresentacional com there, que ocorre com um grupo restrito de verbos intransitivos e é rara em inglês. A última parece ter propriedades diferentes dependendo do peso estrutural do sujeito pós-verbal (cf. Culicover \& Levine, 2001). Nesta secção, apenas descreveremos as propriedades da 
construção apresentacional com there que ocorre com sujeitos leves, visto que é sobre a aquisição deste tipo de estrutura que o presente estudo se debruça. Por facilidade de exposição, doravante, a forma "leve" da construção apresentacional com there será simplesmente designada por "construção com there".

Esta construção tem como função discursiva expressar a existência ou surgimento de uma entidade (num dado cenário) (cf. Breivik, 1981; Kuno \& Takami, 2004) e tem uma interpretação tética, i.e., é interpretada como um todo, um bloco informacional, em que nenhum constituinte tem o estatuto de tópico ou qualquer tipo de destaque informacional (Hartmann, 2008; Sasse, 1987; Zubizarreta \& Nava, 2011). Por este motivo, a construção com there só é discursivamente adequada em contextos de foco largo:

a. Foco largo: A: What happened next? B: There appeared a ship (on the horizon).

b. Foco estreito: A: What appeared (on the horizon)? B:??There appeared a ship (on the horizon).

c. Foco no predicado: A: What did you read in the text about a ship? B: ??There appeared a ship (on the horizon).

Em inglês, esta construção está sujeita a várias restrições gramaticais, das quais destacamos duas: só é compatível com o expletivo there na posição canónica de sujeito (4) (restrição léxico-sintática) e tem de ocorrer ou com um verbo inacusativo ${ }^{4}$, como appear (3a), ou com um inergativo que expresse uma atividade prototípica do referente do sujeito (doravante, inergativo redundante), como wave em (5a) ou rule em (5c). ${ }^{5}$ Se assumirmos com Mendikoetxea (2006) que os verbos inergativos redundantes se comportam semântica e sintaticamente mais como inacusativos do que como verdadeiros inergativos ${ }^{6}$, podemos concluir que a construção com there está sujeita a uma restrição de inacusatividade. Esta restrição envolve a interface léxicosintaxe, uma vez que, tal como Sorace (2006: 111) nota, "there are two sides to the split intransitivity question: a syntactic side (the structural configuration that determines unaccusativity or unergativity) and a lexicon-syntax interface side (the mapping system that decides the syntactic behaviour of any given verb)".

*It appeared a ship on the horizon. / *Appeared a ship on the horizon.

a. There waved a tattered banner from the flagpole. (Lumsden, 1988: 37)

b. ??There waved a bearded student from the roof. (Lumsden, 1988: 37)

c. And in that city there ruled a Queen. (http://www.mit.edu/people/yandros/nada.html)

Além de estar sujeita a uma restrição léxico-sintática, a distribuição dos verbos na construção com there é condicionada por fatores discursivos. Para ser admitido, o verbo tem de ser compatível com a função apresentacional deste tipo de construção, o que, na prática, significa que o verbo deve acrescentar pouca ou nenhuma informação para além da existência/surgimento do referente do sujeito (cf. Kuno \& Takami, 2004). Por outras palavras, tem de ser informacionalmente leve (Levin \& Rappaport Hovav, 1995; Ward, Birner, \& Huddleston, 2002). Esta condição discursiva é satisfeita pelos verbos inacusativos de existência e aparecimento (e.g., arrive, come, appear - para uma lista completa, cf. Levin, 1993), que intrinsecamente têm uma função apresentacional, e pelos verbos inergativos redundantes, que, por expressarem uma ação prototípica do sujeito, estão reduzidos a uma função essencialmente apresentacional/existencial. Ao contrário destes verbos, os inacusativos de mudança de estado (e.g., melt, break - para uma lista completa, cf. Levin, 1993) são, geralmente, incompatíveis com a função apresentacional da construção com there, pois aquilo que derrete ou se parte desaparece e, portanto, deixa de ser apresentável num dado cenário espácio-temporal. Por

\footnotetext{
${ }^{4}$ Verbo cujo único argumento é gerado em posição de objeto e tem o papel de temático de tema ou de paciente.

${ }^{5}$ Há alguma variação entre falantes nativos quanto à aceitabilidade de inergativos redundantes nesta estrutura. Alguns falantes parecem aceitar apenas esta estrutura com inacusativos de existência e aparecimento.

${ }^{6}$ Verbo cujo único argumento é gerado em Spec, VP e, tipicamente, tem o papel de temático de agente.
} 
este motivo, esta subclasse de inacusativos tende a ser rejeitada na construção com there (6) (cf. Kuno \& Takami, 2004; Levin, 1993; Levin \& Rappaport Hovav, 1995). ${ }^{7}$

$$
\text { ??There melted a lot of snow on the streets of Chicago. (Levin, 1993: 90) }
$$

Tal como o inglês, o francês admite inversão com um expletivo expresso, $i l$, com verbos inacusativos de existência e aparecimento (7a) e com inergativos redundantes ${ }^{8}(7 \mathrm{~b})$, mas não com inacusativos de mudança de $\operatorname{estado}^{9}$ (7c) e inergativos não redundantes (7d) (Carlier, 2005; Jones, 1996; Mackenzie, 2006). Este tipo de inversão tem uma interpretação tética (Sasse, 1987; Zubizarreta \& Nava, 2011) e ocorre apenas em contexto de foco largo, como se mostra em (8) (cf. Belletti \& Bianchi, 2016: fn45).

a. Il est arrivé une lettre.

EXPL chegou uma carta

b. Il souffle un vent chaud. (Mackenzie, 2006: 33)

EXPL sopra um vento quente

c. ??Il s'est brisé un verre dans la cuisine.

EXPL se partiu um copo na cozinha

d. ??Il a vomi un garçon à côté de notre table.

EXPL vomitou um rapaz ao lado da nossa mesa
a. Foco largo:
A: Que s'est-il passé? o que se passou
B: Il est arrivé trois filles.

\section{b. Foco estreito:}
A: Qui est arrivé? B: ??Il est arrivé trois filles. quem chegou
EXPL chegou três raparigas

c. Foco no predicado: A: Que sais-tu à propos de trois filles? B: ??Il est arrivé trois filles. o que sabes sobre três raparigas EXPL chegou três raparigas

(adaptado de Belletti \& Bianchi, 2016: fn45)

Ao contrário do que acontece em inglês e francês, em PE, não existe inversão com expletivo expresso (9), porque esta língua tem um valor positivo para o parâmetro de sujeito nulo. Em PE, os juízos téticos são tipicamente expressos através da ordem VS(XP) (Kato \& Martins, 2016; Lobo \& Martins, 2017; Martins \& Costa, 2016), que, segundo análises de Costa (2004) e Sheehan (2007), envolve um expletivo nulo. A ordem VS(XP) é permitida com todo o tipo de verbos intransitivos, incluindo inacusativos de mudança de estado (10a) e inergativos não redundantes (10b).

$$
\begin{aligned}
& \text { A: O que se passa? } \\
& \text { B: *Ele apareceu uma fissura na parede. / Apareceu uma fissura na parede. }
\end{aligned}
$$

a. Partiu-se um copo na cozinha./ ??There broke a glass in the kitchen. / ??Il s'est brisé un verre dans la cuisine.

\footnotetext{
${ }^{7}$ Apenas é aceite em casos como os apresentados em (i), em que a inserção do advérbio slowly sugere que a entidade que está a sofrer a mudança de estado ainda existe e, portanto, ainda é apresentável num cenário espácio-temporal (Bolinger, 1977; Kuno \& Takami, 2004): (i) i. ??There dissolved a mass of ectoplasm. Ii. There slowly dissolved a mass of ectoplasm. (Bolinger, 1977: 97)

${ }^{8}$ Há alguma variação entre falantes nativos de francês quanto à aceitabilidade de inergativos redundantes nesta estrutura. Alguns falantes parecem aceitar esta estrutura apenas com inacusativos de existência e aparecimento.

${ }^{9}$ Em alguns estudos, como o de Labelle (1992), propõe-se que verbos de mudança de estado são compatíveis com a inversão com o expletivo il na sua forma reflexiva (e.g., se casser 'partir-se'), mas não na sua forma não reflexiva (e.g., casser 'partir'). Contudo, todos os falante nativos de francês que consultei $(n=10)$ rejeitam inversão com as duas formas destes verbos, embora reconheçam que, num par mínimo de frases como (i), a frase (ia) é pior do que a (ib).

(i) a. ??Il s'est cassé plusieurs branches. b. *Il a cassé plusieurs branches.

EXPL se partiu vários ramos EXPL partiu vários ramos
} 
b. Vomitou um rapaz junto à nossa mesa. / ??There vomited a boy next to our table. / ??Il a vomi un garçon à côté de notre table.

\section{O presente estudo}

\subsection{Questões de investigação e predições}

À luz do atual estado da arte, sintetizado na secção 2, e tendo em conta as características da inversão com expletivo em inglês, francês e PE, descritas na secção 3, formulámos as seguintes questões de investigação:

1. Será que os falantes quase nativos e/ou avançados de inglês exibem problemas relativamente a uma propriedade léxico-sintática como o tipo de expletivo admitido na construção com there?

2. Será que os falantes quase nativos e avançados de inglês exibem problemas quanto a propriedades da construção com there que envolvem a interface com o discurso, como (i) as condições léxicosintático-discursivas que governam a distribuição de verbos intransitivos nesta construção e (ii) as condições discursivas que determinam se uma construção com there é adequada num dado contexto?

3. Se os falantes quase nativos e/ou avançados exibirem problemas na aquisição da construção com there, serão eles um efeito do processamento bilingue e/ou de outros fatores, como a L1?

A HI e a HLI fazem predições diferentes em relação a estas questões, tal como mostra a seguinte tabela:

\begin{tabular}{|c|c|c|}
\hline $\begin{array}{c}\text { Questão de } \\
\text { investigação }\end{array}$ & Predições da HI & Predições da HLI \\
\hline 1 & $\begin{array}{l}\text { As propriedades léxico-sintáticas da } \\
\text { construção com there não causarão } \\
\text { dificuldades a falantes quase nativos de } \\
\text { inglês, independentemente da sua L1. Não } \\
\text { é, contudo, de excluir a possibilidade de os } \\
\text { falantes em nível avançado terem } \\
\text { problemas deste tipo. }\end{array}$ & $\begin{array}{l}\text { Os falantes franceses e portugueses de inglês exibirão } \\
\text { divergência em relação ao tipo de expletivo admitido } \\
\text { em construções com there com verbos que não be, } \\
\text { visto que esta estrutura é muito rara em inglês e a sua } \\
\text { L1 é diferente da L2 (o francês usa il, que é o } \\
\text { equivalente de it, e o PE usa expletivo nulo). }\end{array}$ \\
\hline 2 & $\begin{array}{l}\text { Os falantes portugueses e franceses de } \\
\text { inglês exibirão opcionalidade relativamente } \\
\text { a propriedades que envolvem a interface } \\
\text { sintaxe-discurso nos níveis avançado e } \\
\text { quase nativo. }\end{array}$ & $\begin{array}{l}\text { Os falantes franceses de inglês num nível quase nativo } \\
\text { convergirão com a L2, mas os falantes portugueses } \\
\text { exibirão divergência relativamente às propriedades } \\
\text { sintático-discursivas da construção com there que são } \\
\text { diferentes na sua L1 e na L2. }\end{array}$ \\
\hline 3 & $\begin{array}{l}\text { Na base dos problemas dos falantes quase } \\
\text { nativos e avançados estarão ineficiências de } \\
\text { processamento associadas ao bilinguismo. } \\
\text { Por isso, ocorrerão problemas } \\
\text { independentemente de a L1 ser ou não } \\
\text { diferente da L2. }\end{array}$ & $\begin{array}{l}\text { Na base dos problemas dos falantes avançados e quase } \\
\text { nativos com respeito a este tipo infrequente de } \\
\text { inversão estará a influência da L1 sobre as suas } \\
\text { representações da L2 e não ineficiências de } \\
\text { processamento associadas ao bilinguismo. }\end{array}$ \\
\hline
\end{tabular}

Tabela 1. Predições da HI e da HLI sobre as questões de investigação do presente trabalho 


\subsection{Participantes}

Participaram neste estudo 26 falantes monolingues de inglês, 26 falantes de inglês L2-francês L1 e 28 falantes de inglês L2-PE L1. Os falantes nativos de inglês eram estudantes universitários, com idades compreendidas entre os 18 e os 52 anos, que viviam, à data do estudo, na Escócia e não tinham proficiência avançada em qualquer outra língua, apesar de terem recebido instrução em, pelo menos, uma L2 durante o seu percurso escolar. Os falantes nativos de PE e de francês eram estudantes universitários que começaram a ser expostos ao inglês em contexto escolar entre os 8 e os 13 anos, mas só passaram a ter uma exposição mais intensa a esta língua na adolescência. Tendo em conta estes factos, e assumindo com Meisel (2008: 59) que os indivíduos que começam a ter exposição a uma L2 numa idade igual ou superior a 8 anos são aprendentes "adultos", consideramos que todos os falantes não nativos de inglês que participaram no presente estudo podem ser classificados como aprendentes adultos de L2. Estes falantes foram divididos em quatro grupos: (i) um grupo de franceses com nível avançado em inglês $(n=15)$, (ii) um grupo de franceses com nível quase nativo em inglês $(n=11)$, (iii) um grupo de portugueses com nível avançado em inglês ( $n=17)$ e (iv) um grupo de portugueses com nível quase nativo em inglês $(n=11)$. Os detalhes sobre o perfil sociolinguístico de cada grupo são apresentados na tabela 2 .

\begin{tabular}{|c|c|c|c|c|c|c|c|c|}
\hline \multirow[t]{2}{*}{ Grupo } & \multicolumn{2}{|r|}{ Idade } & \multicolumn{2}{|c|}{$\begin{array}{c}\text { Idade de início de } \\
\text { exposição regular ao } \\
\text { inglês }\end{array}$} & \multicolumn{2}{|c|}{$\begin{array}{c}\text { Anos de } \\
\text { aprendizagem do } \\
\text { inglês }\end{array}$} & \multicolumn{2}{|c|}{$\begin{array}{c}\text { Anos de residência em } \\
\text { países anglófonos }\end{array}$} \\
\hline & Média & Desvio padrão & Média & Desvio padrão & Média & Desvio padrão & Média & Desvio padrão \\
\hline \multicolumn{9}{|c|}{ PE L1 - ING L2 } \\
\hline Quase nativos & 31,09 & 9,23 & 9,09 & 1,08 & 12,64 & 3,42 & 3,47 & 4,85 \\
\hline Avançados & 24,88 & 8,86 & 8,94 & 1,26 & 10,06 & 2,44 & 0,60 & 0,89 \\
\hline \multicolumn{9}{|l|}{$\begin{array}{l}\text { FR L1 - ING } \\
\text { L2 }\end{array}$} \\
\hline Quase nativos & 21,73 & 2,60 & 11,09 & 1,38 & 8,36 & 2,67 & 3,73 & 3,29 \\
\hline Avançados & 21,00 & 1,59 & 9,33 & 1,66 & 11,27 & 2,05 & 0,93 & 0,39 \\
\hline
\end{tabular}

Tabela 2. Dados biográficos sobre os falantes de inglês L2

O nível de proficiência dos falantes de inglês L2 foi avaliado através de uma versão adaptada do procedimento de seleção usado por Sorace \& Filiaci (2006), que foi originalmente desenhado por White \& Genesee (1996). No âmbito desta avaliação, todos os participantes foram entrevistados individualmente em inglês durante 10 minutos. Na entrevista, foram usados cartoons para induzir produção espontânea sobre um leque variado de tópicos. Uma amostra da produção de cada participante (com cerca de 2 minutos) foi, subsequentemente, selecionada, de modo aleatório, e avaliada por três falantes monolingues de inglês (britânico) com algum treino em linguística, tendo em conta os seguintes critérios: pronúncia, morfologia, sintaxe, vocabulário, fluência e impressão geral. Na grelha de avaliação dada aos avaliadores, cada critério era acompanhado de uma linha contínua de $9 \mathrm{~cm}$, com a designação "não nativo" na ponta esquerda e "nativo" na ponta direita, devendo o avaliador assinalar com uma cruz o grau de proximidade do excerto ao nível nativo. Para assegurarmos que a ponta nativa da escala era interpretada tendo como ponto de referência verdadeiros falantes nativos de inglês, foram misturados, de modo aleatório, excertos de entrevistas com falantes nativos de origem australiana, norte-americana, inglesa e escocesa com os excertos das entrevistas dos falantes de L2. Após a conclusão de todas as avaliações, os registos dos avaliadores foram transformados em valores 
discretos, através da sobreposição de um acetato com uma linha de $9 \mathrm{~cm}$ dividida numa escala de 18 pontos (1 ponto por cada $0.5 \mathrm{~cm}$ ). Os falantes de inglês L2 a quem todos os avaliadores atribuíram entre 16 e 18 pontos (os pontos dentro do primeiro $\mathrm{cm}$ a contar da ponta nativa) nos critérios sintaxe, morfologia e vocabulário e 15 ou mais pontos nos restantes critérios $^{10}$, com o máximo de uma exceção ${ }^{11}$, foram considerados quase nativos. Aqueles que receberam entre 14 e 16 pontos nos critérios sintaxe, morfologia e vocabulário e 12 ou mais pontos nos outros critérios, com o máximo de uma exceção, foram classificados como avançados.

\subsection{Desenho experimental}

Todos os participantes foram sujeitos a uma bateria de tarefas experimentais que testaram as seguintes variáveis: (i) o tipo de expletivos admitidos na posição de sujeito de ordens VS (it vs. there); (ii) o tipo de verbos intransitivos admitidos na construção com there (inacusativo de existência e aparecimento vs. inacusativo de mudança de estado vs. inergativo redundante vs. inergativo não redundante); e (iii) o tipo de contexto discursivo em que a construção é aceitável (foco largo vs. foco estreito no sujeito vs. foco no predicado). Todas as tarefas incluíam 6 itens por condição e tantos distratores quanto itens experimentais. Nestes itens, foram usados PP locativos indefinidos com 3 palavras (exceto nas condições "foco estreito" e "foco no predicado"), verbos no passado simples e sujeitos indefinidos com 3 palavras (exceto na tarefa de priming, em que tinha 2). Nas tarefas que testavam a variável "tipo de verbo", foram fornecidos contextos que forçavam toda a construção com there a ser interpretada como foco, uma vez que este é o contexto discursivo em que esta estrutura é mais amplamente aceite. Por seu lado, nas tarefas sobre as variáveis "tipo de contexto discursivo" e "tipo de expletivo", foram usados inacusativos de existência e aparecimento em todos os itens experimentais. A tabela 3 apresenta exemplos de itens para cada uma das condições testadas.

\begin{tabular}{|c|c|}
\hline Tipo de verbo intransitivo & Tipo de contexto discursivo \\
\hline $\begin{array}{l}\text { Inacusativo de existência e aparecimento: A: Tell me what } \\
\text { happened afterwards in the story. }{ }^{12} \mathrm{~B} \text { : During the night... } \\
\text { there appeared a scary ghost near a tombstone. }\end{array}$ & $\begin{array}{l}\text { Contexto de foco estreito no sujeito: A: Who appeared } \\
\text { on the stage? B: There appeared a famous writer on the } \\
\text { stage. }\end{array}$ \\
\hline $\begin{array}{l}\text { Inacusativo de mudança de estado: A: Tell me what } \\
\text { happened afterwards in the story. B: During the night... there } \\
\text { broke a large window in a room. }\end{array}$ & $\begin{array}{l}\text { Contexto de foco no predicado: A: Why is everybody } \\
\text { talking about our } 7^{\text {th }} \text { graders? What did they do? B: } \\
\text { There appeared some of them on BBC News. }\end{array}$ \\
\hline $\begin{array}{l}\text { Inergativo redundante: A: Tell me what happened afterwards } \\
\text { in the story. B: During the night... there fluttered a white flag } \\
\text { over a fort. }\end{array}$ & $\begin{array}{l}\text { Contexto de foco largo: A: What happened afterwards } \\
\text { in the story? B: There came a loud roar from a cave. }\end{array}$ \\
\hline $\begin{array}{l}\text { Inergativo não redundante: } \mathrm{A}: \text { Tell me what happened } \\
\text { afterwards in the story. } \mathrm{B}: \text { During the night... there vomited } \\
\text { many drunken men in a corner. }\end{array}$ & \\
\hline \multicolumn{2}{|c|}{ Tipo de sujeito expletivo } \\
\hline $\begin{array}{l}\text { There: = aos itens que testaram inacusativos de existência } \\
\text { intransitivo" }\end{array}$ & cimento nas tarefas sobre a variável "tipo de verbo \\
\hline
\end{tabular}

Tabela 3. Exemplos de itens por condição

\footnotetext{
${ }^{10}$ Esta pontuação é semelhante à atribuída aos falantes nativos, que, ocasionalmente, receberam avaliações de 15 em critérios como fluência.

${ }^{11}$ As exceções são tipicamente no critério pronúncia.

${ }^{12}$ Usámos a pergunta "tell me what happened afterwards in the story" para tornar claro que a construção com there está a ser usada no contexto de narração de uma história, que é um contexto em que esta construção é adequada.
} 
Cada uma das variáveis foi testada através de, pelo menos, dois tipos de tarefas experimentais. Por um lado, as variáveis "tipo de contexto discursivo" e "tipo de expletivo" foram testadas através de tarefas drag \& drop e de juízos de aceitabilidade rápidos. Por outro, a variável "tipo de verbo" foi testada através de uma tarefa drag \& drop, uma tarefa de priming sintático e uma tarefa de juízos de aceitabilidade rápidos. Todas foram administradas presencialmente em dois computadores portáteis.

Na tarefa drag \& drop, era apresentado aos participantes um contexto linguístico e pedido que usassem os blocos de palavras no ecrã, a fim de criarem um mínimo de 1 e o máximo de 4 continuações para o contexto fornecido. Dois tipos de blocos de palavras eram fornecidos: blocos obrigatórios, marcados a vermelho, e blocos opcionais, marcados a verde. Os últimos continham sempre there e it.

$\mathrm{Na}$ tarefa de priming sintático ${ }^{13}$, que tem por base o modelo das tarefas de Schutter (2013), primeiro, os participantes tinham de ler em voz alta uma frase que aparecia no ecrã do computador durante 4 segundos - a frase prime. Em seguida, surgia uma imagem e era pedido aos participantes que indicassem, em 4 segundos, se esta correspondia ou não à frase lida em voz alta. Por último, aparecia uma outra imagem no ecrã, a qual tinha de ser descrita em 5 segundos, com recurso a uma única frase. Tendo em conta os resultados da investigação sobre priming sintático ( Branigan, 2007; Pickering \& Ferreira, 2008; Schutter, 2013), esperavase que, se a estrutura usada na frase prime fosse possível na gramática mental do falante, este tenderia a usá-la para descrever a imagem final de cada item.
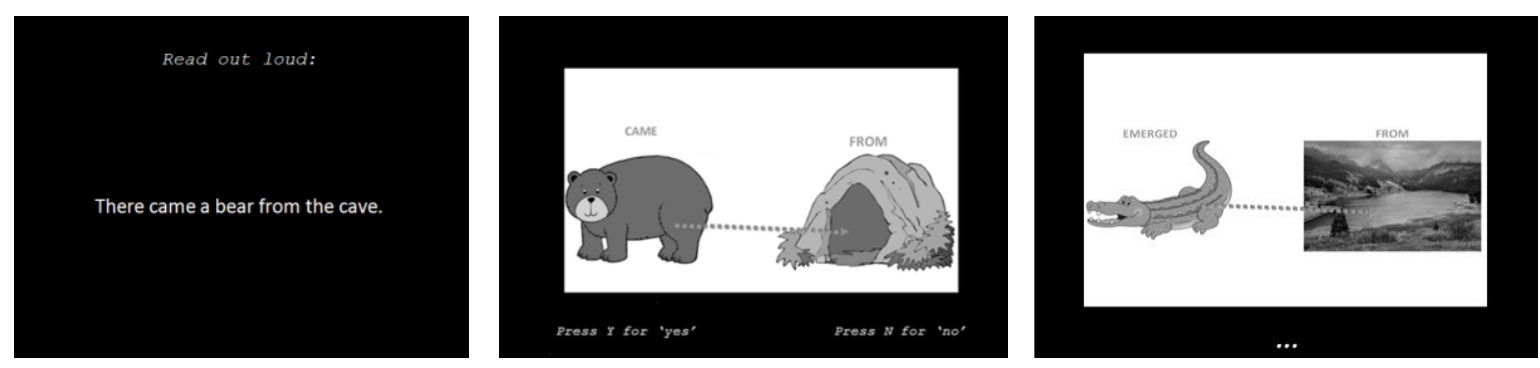

Figura 1. Item de exemplo da tarefa de priming sintático

Por fim, na tarefa de juízos de aceitabilidade rápidos, os participantes tinham de avaliar o mais depressa possível a aceitabilidade de uma frase que era apresentada palavra a palavra no centro do ecrã a um ritmo de $400 \mathrm{~ms}$ por palavra. ${ }^{14}$ A avaliação era feita numa escala de 1 a 5, em que 1 correspondia a "totalmente inaceitável" e 5 a "totalmente aceitável". Antes de aparecer a frase a ser avaliada, era pedido aos participantes que lessem silenciosamente o contexto que a antecedia, o qual era apresentado como um único bloco de palavras, sem qualquer limite de tempo.

Dadas estas características, as tarefas que usámos não eram igualmente exigentes em termos de processamento linguístico. Enquanto, nas tarefas drag \& drop, os participantes tinham tempo suficiente para reanalisar as frases, acederem ao seu conhecimento linguístico e monitorizarem as suas repostas, nas restantes tarefas experimentais, a apresentação rápida dos estímulos e a rapidez exigida na resposta colocavam algum peso sobre os recursos de processamento do participante e não permitiam reanálise (Bader \& Haussler, 2010; Hopp, 2007; Schütter, 2013). Por isso, estas poderão captar o tipo de opcionalidade predito pela HI, que pode não ser detetável em tarefas sem pressão de tempo, como a tarefa drag \& drop. O recurso a diferentes tipos de tarefas é, assim, fundamental para obtermos um retrato mais completo do que se passa nas interfaces em L2.

\footnotetext{
${ }^{13}$ Priming sintático refere-se à tendência que os falantes têm de repetir o tipo de estrutura frásica usada numa frase imediatamente anterior, sem relação semântica com a frase que estão a produzir.

${ }^{14}$ Este é o ritmo tipicamente usado neste tipo de tarefas, uma vez que se assume que $400 \mathrm{~ms}$ é uma janela de tempo suficiente para os falantes completarem todos os processos de compreensão normais (cf. Bader \& Häussler, 2010; Hopp, 2007).
} 


\subsection{Análise dos dados}

A análise estatística dos dados foi realizada com modelos de efeitos mistos, em que foram computados como efeitos fixos as variáveis grupo, tipo de expletivo, tipo de verbo e tipo de contexto discursivo e como efeitos aleatórios as variáveis participantes e itens. Foram realizados dois tipos de análises com estes modelos: within-group e between-groups. Os efeitos fixos foram codificados com os seguintes códigos contrastivos: 0.5 vs. -0.5 para contrastar dois níveis do mesmo efeito fixo (e.g., grupo de controlo $=0.5 v$ s. grupo avançado de falantes de inglês L2 - PE L1=-0.5) e $0.5 v s$. -0.25 para contrastar um nível com dois níveis do mesmo efeito fixo (e.g., contexto de foco largo $=0.5$ vs. foco estreito $=-0.25+$ foco no predicado $=-0.25$ ). Seguindo Cunnings (2012) e Linck e Cunnings (2015), as análises incluíram interceções aleatórias para participantes e itens, declives aleatórios por participante para as variáveis within-subject e declives aleatórios por item para a variável grupo (mas apenas nas análises between-groups). A análise estatística foi conduzida em $\mathrm{R}$, usando o pacote lme4. Mais especificamente, foi usada a função lmer (modelo misto linear) para a análise dos resultados das tarefas de juízos de aceitabilidade rápidos e a função glmer (modelo misto linear generalizado), com a especificação "family=binomial", para a análise dos dados das restantes tarefas, uma vez que estas produzem resultados binários - presença/ausência de inversão com there (codificados como VS $=1 \mathrm{e}$ ausência de VS $=0$ ). Dado que a função glmer gera output com valores de $p$ e a função lmer apenas gera valores de $t$, usámos como medidas de significância os valores de $p$ e $t$. Como é habitual na literatura (cf. Linck \& Cunnings, 2015), um efeito fixo foi considerado estatisticamente significativo sempre que $p$ é inferior ou igual a 0.05 ou o valor absoluto de $t$ é superior ou igual a 2.00 .

\section{Resultados}

\subsection{Estudo 1: Tipo de expletivo admitido na posição de sujeito de ordens VS}

No presente estudo, o mapeamento entre léxico e sintaxe que determina a gramaticalidade de there e a agramaticalidade de it em estruturas de inversão sujeito-verbo foi uma fonte de problemas para todos os grupos de falantes avançados de inglês L2, mas não para os grupos de falantes quase nativos.

Comecemos por analisar os resultados da tarefa drag \& drop. Nesta tarefa, todos os grupos preferiram there a it (ING L1: estimativa $=5.0799, \mathrm{EP}=1.4783, p<.001$; FR QN: estimativa $=4.7605, \mathrm{EP}=.8937, p<.001$; $\mathrm{PE} \mathrm{QN}$ : estimativa $=3.005, \mathrm{EP}=1.692, p=.0558^{15}$; $\mathrm{PE} \mathrm{AV}$ : estimativa $\left.=1.4602, \mathrm{EP}=.6617, p=.027331\right)^{16}$, exceto o grupo de franceses com um nível avançado em inglês, que não fez nenhuma distinção entre estes expletivos (estimativa=1.753, EP=3.726, $p=.6380$ ). Como é mostrado na figura 2, apesar de exibir uma preferência por usar there para preencher a posição canónica de sujeito de estruturas VS, o grupo de portugueses com nível avançado em inglês produziu significativamente mais estruturas deste tipo com it do que o grupo controlo (estimativa $=5.3887, \mathrm{EP}=1.6114, p<.001$ ).

\footnotetext{
15 Aqui e em todos os contextos em que o valor de $p$ é menor do que 1.0 e maior do que 0.05 , $p$ é considerado marginalmente significativo.

${ }^{16}$ EP=erro padrão; ING L1=inglês L1; FR QN=franceses com nível quase nativo em inglês; PE QN= falantes de PE com nível quase nativo em inglês; FR AV=franceses com nível avançado em inglês; PE QN= falantes de PE com nível avançado em inglês.
} 


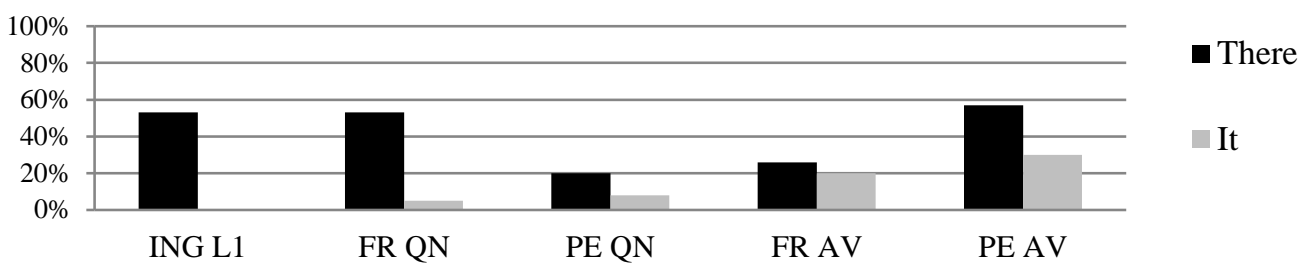

Figura 2. \% de estruturas de inversão produzidas com verbos inacusativos de existência e aparecimento na tarefa drag \& drop por tipo de expletivo

$\mathrm{Na}$ tarefa de juízos de aceitabilidade rápidos, os resultados foram ligeiramente diferentes. Aqui todos os grupos de falantes avançados de inglês L2 aceitaram inversão com it significativamente mais do que o grupo de controlo (FR AV: estimativa=1.1644, $\mathrm{EP}=.4050, t=2.875$; PE AV: estimativa=1.3122, $\mathrm{EP}=.3377, t=3.885$ ) e trataram it e there do mesmo modo (dif. entre it e there: $t \mathrm{~s} \leq 1.476$ ). Só os grupos de falantes quase nativos tiveram um desempenho semelhante ao do grupo de controlo. Como é ilustrado na figura 3, os falantes quase nativos rejeitaram inversão com o expletivo it tanto quanto os controlos (controlos vs. cada grupo quase nativo: $t s \leq .962$ ). Além disso, aceitaram a ordem VS significativamente mais quando a posição canónica de sujeito era ocupada pelo expletivo there do que quando it estava nessa posição (FR QN estimativa=1.0152, $\mathrm{EP}=.3447, t=2.945$; PE QN estimativa=.9697, $\mathrm{EP}=.4034, t=2.104)$.

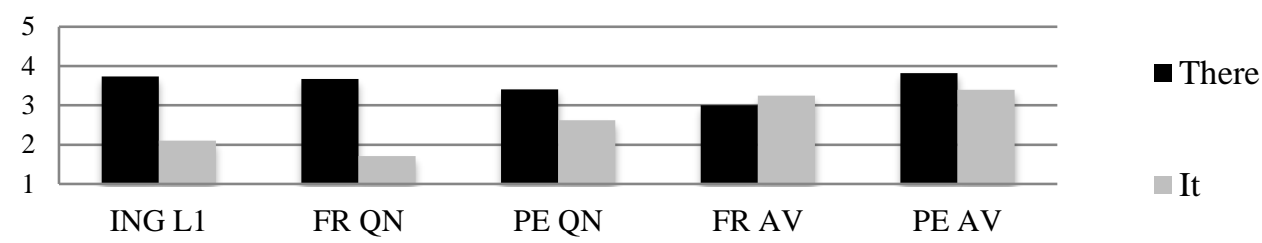

Figura 3. Média de aceitação de inversão com there e it (com verbos inacusativos de existência e aparecimento) na tarefa de juízos de aceitabilidade rápidos

\subsection{Estudo 2: Tipo de verbos intransitivos admitidos na construção com there}

As experiências sobre os tipos verbos intransitivos admitidos na construção com there produziram resultados diferentes dos reportados na secção anterior. $O$ único grupo que conseguiu diferenciar consistentemente os tipos de verbos que são compatíveis com esta construção (i.e., inacusativos de existência e aparecimento e inergativos redundantes) dos que não o são (i.e., inacusativos de mudança de estado e inergativos não redundantes) foi o grupo de falantes monolingues de inglês (tarefa drag \& drop: estimativa=1.2558, EP=.3981, $p=.00161$; tarefa de priming sintático: estimativa=-2.822, EP=1.532, $p=.0655$; tarefa de juízos de aceitabilidade: estimativa=-.9367, EP=.2091, $t=-4.48$ ). Como será mostrado em seguida, todos os outros grupos manifestaram opcionalidade em, pelo menos, uma tarefa experimental.

Consideremos, em primeiro lugar, os resultados da tarefa drag \& drop, apresentados na figura 4. Nesta tarefa, apenas o grupo de franceses com nível quase nativo em inglês foi capaz de distinguir os verbos que são aceitáveis na construção com there daqueles que são inaceitáveis (estimativa=-1.6513, EP=.6684, $p=.0135$ ). Os restantes grupos de L2 não conseguiram fazer tal distinção ( $p$ s $\geq .10532$ ). 


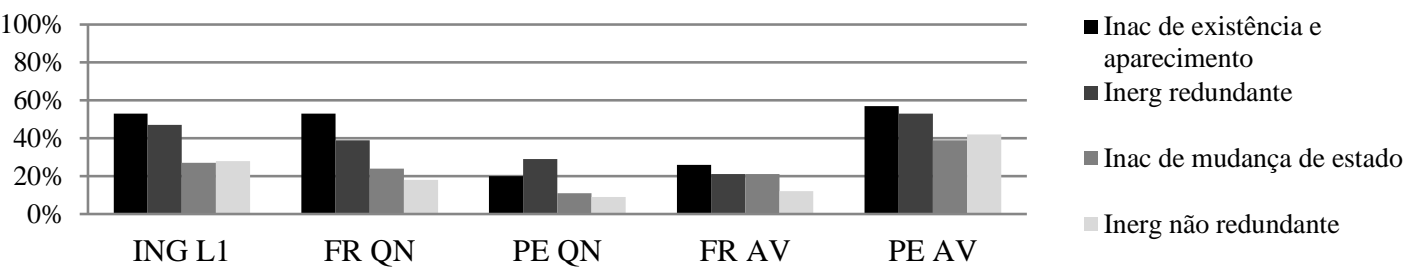

Figura 4. \% de construções com there produzidas na tarefa drag \& drop por tipo de verbo

$\mathrm{Na}$ tarefa de priming sintático, as taxas de produção da construção com there foram muito inferiores às observadas na tarefa $d r a g \& d r o p$, mesmo no grupo de controlo. Possivelmente, isto aconteceu porque a tarefa de priming que aplicámos envolvia produção oral de frases descontextualizadas e, em inglês, a construção com there é maioritariamente usada em géneros literários. A produção de inversão nesta tarefa pode, por isso, ter sido percecionada pelos participantes como pouco natural, levando a que o efeito de priming sintático que pretendíamos criar tenha sido bloqueado em parte dos itens experimentais. Crucialmente, apesar das baixas taxas de produção de construções com there, nesta tarefa, o grupo de controlo produziu ligeiramente mais inversão com inergativos redundantes e inacusativos de aparecimento do que com os restantes verbos (estimativa=-2.822, $\mathrm{EP}=1.532, p=.0655$ ). Este grupo distinguiu ainda a subclasse de verbos que ocorre mais prontamente em construções com there - a classe de verbos inacusativos de existência e aparecimento - dos outros tipos de verbos $(p s \leq .044)$. Tais distinções não foram feitas pelos grupos de falantes de L2. Como a figura 5 mostra, estes grupos exibiram um comportamento indeterminado (verbos aceitáveis x inaceitáveis: $p \mathrm{~s} \geq .4714$; inac de existência e aparecimento $\mathrm{x}$ restantes verbos: $p \mathrm{~s} \geq .41638$ ).
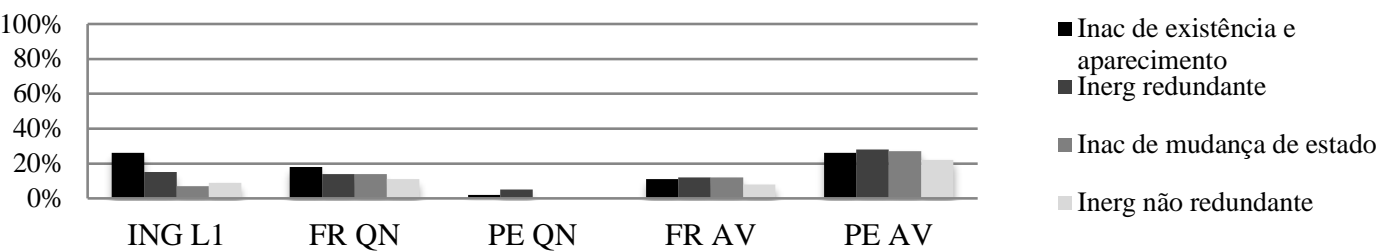

Figura 5. \% de construções com there produzidas na tarefa de priming sintático por tipo de verbo

Olhemos, por fim, para os resultados da tarefa de juízos de aceitabilidade rápidos apresentados na figura 6. Nesta tarefa, os falantes de inglês L2, tal como o grupo de controlo, atribuíram pontuações superiores às construções com there quando o verbo era um inergativo redundante ou um inacusativo de existência e aparecimento do que quando este pertencia às outras classes verbais testadas (verbos aceitáveis $\mathrm{x}$ inaceitáveis: FR QN estimativa=-.5944, EP=.1440, $t=-4.128$; FR AV estimativa=-.6288, EP=.2137, $t=-2.942 ; \mathrm{PE}$ AV estimativa=-.7451, EP=.2427, $t=-3.07$; $\mathrm{PE} \mathrm{QN}$ estimativa=-.5606, $\mathrm{EP}=.2098, t=-2.672$ ). A análise dos resultados individuais, no entanto, revela que, ao contrário do que pode parecer à primeira vista, nem todos os grupos de falantes de L2 tiveram um comportamento alvo na tarefa de juízos de aceitabilidade. Como se pode ver na figura 7 , dentro de cada um dos grupos de nível avançado, mais de $60 \%$ dos falantes teve pontuações medianas superiores ou inferiores a $3 \mathrm{em}$ todas as condições experimentais, o que significa que a maioria dos falantes avançados aceitou ou rejeitou inversão com there com todos os tipos de verbos testados. Nos grupos de falantes quase nativos, as percentagens de falantes com medianas acima ou abaixo de 3 em todas as condições foram menores: $45 \%$ no grupo de quase nativos franceses e $54 \%$ no grupo de quase nativos portugueses. A fim de determinar se existiram, a este respeito, diferenças estatisticamente relevantes entre falantes monolingues e falantes de L2, analisámos estatisticamente os seus resultados individuais, codificados como " $1=$ tem mediana superior ou inferior a $3 \mathrm{em}$ todas as condições" e " $0=$ não tem mediana superior ou 
inferior a 3 em todas as condições", usando um modelo misto linear generalizado (com especificação "family=binomial"). Este mostrou que existem diferenças estatisticamente significativas entre o grupo monolingue e cada um dos grupos de falantes avançados de inglês L2 (FR AV: estimativa=1.4759, EP=.8231, $p=.0730$; PE AV: estimativa=1.35991, $\mathrm{EP}=.67931, p=.0453)$, mas não entre o grupo monolingue e os grupos de quase nativos ( $p \mathrm{~s} \geq .207)$. A inexistência de diferenças estatísticas entre quase nativos e monolingues devese não ao facto de os primeiros não terem tido um desempenho opcional, mas antes ao facto de os últimos terem exibido alguma opcionalidade. Possivelmente, por a construção com there com verbos que não be ser muito rara, os monolingues tinham juízos menos definidos quanto à propriedade em teste, o que levou alguns a exibir opcionalidade, quando colocados sob pressão.

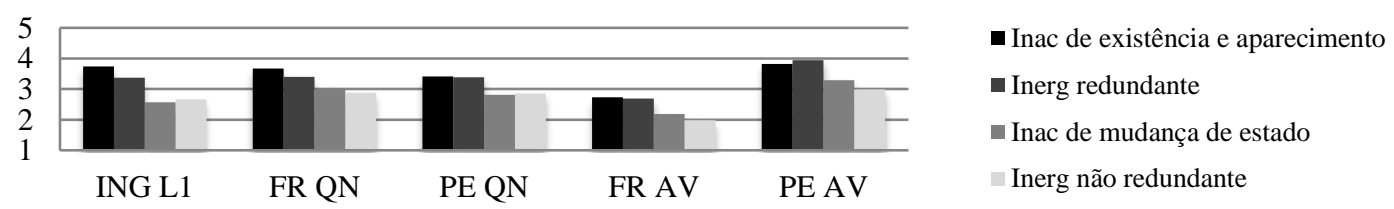

Figura 6. Média de aceitação de construções com there na tarefa de juízos de aceitabilidade rápidos por tipo de verbo (escala 1-5)

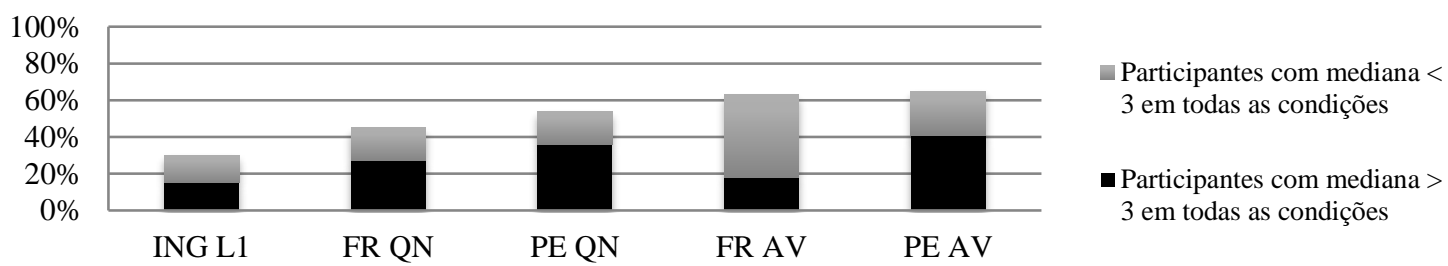

Figura 7. \% de falantes com mediana $>$ ou $<3$ em todas as condições experimentais da tarefa de juízos de aceitabilidade

\subsection{Estudo 3: Tipo de contextos discursivos em que a construção com there é admitida}

À semelhança do que se observou no conjunto de tarefas experimentais apresentadas em 5.2, no estudo que se debruça sobre o tipo de contextos discursivos (in)compatíveis com a construção com there, os falantes monolingues de inglês tiveram um padrão de comportamento semelhante em tarefas com diferentes graus de exigência do ponto de vista do processamento linguístico. Em todas as tarefas, permitiram inversão com there significativamente mais nos contextos de foco largo do que nos restantes contextos (tarefa drag \& drop: estimativa=-3.3964, EP=.8057, $p<.001$; tarefa de juízos de aceitabilidade: estimativa=-1.5422, EP=.4605, $t=-$ 3.349). Ao contrário do grupo monolingue, os grupos de falantes de L2 não conseguiram distinguir, de forma consistente, os contextos em que este tipo de inversão é discursivamente adequado daqueles em que não o é.

Analisemos o comportamento dos grupos de falantes de inglês L2 tarefa a tarefa. Como a figura 8 torna claro, na tarefa drag \& drop, nenhum destes grupos foi capaz de distinguir o contexto discursivo em que as construções com there são adequadas (i.e., foco largo) de todos aqueles que são desadequadas ( $p$ s $\geq .2261)$. Já, na tarefa de juízos de aceitabilidade rápidos, os resultados foram, à primeira vista, ligeiramente melhores. Como se pode ver na figura 9, todos os grupos, à exceção do grupo de portugueses com nível avançado em inglês, fizeram uma distinção estatisticamente significativa entre os contextos de foco largo e os de foco no predicado (FR QN estimativa=-.5222, EP=.3074, $t=-1.699$; PE QN estimativa=-.6818, EP=.3947, $t=-1.727$; 
FR AV: estimativa=-.8030, EP=.2551, $t=-3.148 ; \mathrm{PE}$ AV: estimativa=-.4412, $\mathrm{EP}=.3419, t=-1.29) .{ }^{17} \mathrm{O}$ contraste entre foco largo e estreito, contudo, levantou problemas a todos os grupos. Por um lado, os grupos de franceses e o grupo de portugueses quase nativos trataram estes contextos do mesmo modo $(t \mathrm{~s} \leq 1.481)$. $\mathrm{O}$ grupo de portugueses com nível avançado em inglês, por outro lado, aceitou mais construções com there em contextos de foco de estreito do que de foco largo (estimativa=.6569, EP=.2831, $t=2.321$ ). Só o grupo monolingue exibiu uma preferência por contextos de foco largo em detrimento de contextos de foco estreito (estimativa=-0.7000, EP=0.3661, $t=-1.912$ ).

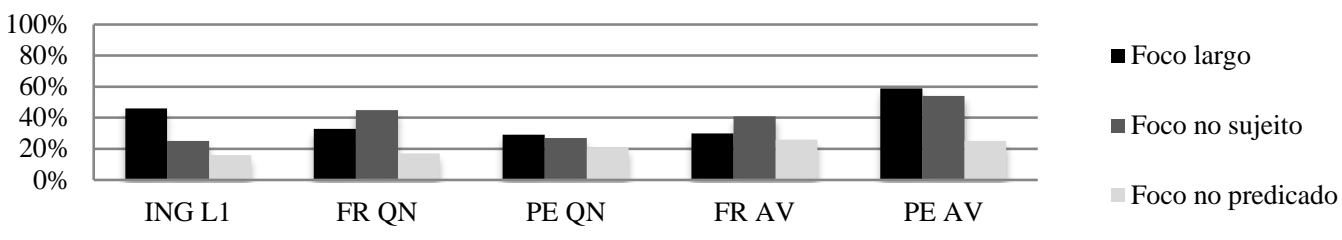

Figura $8 . \%$ de construções com there produzidas na tarefa drag \& drop por tipo de contexto discursivo

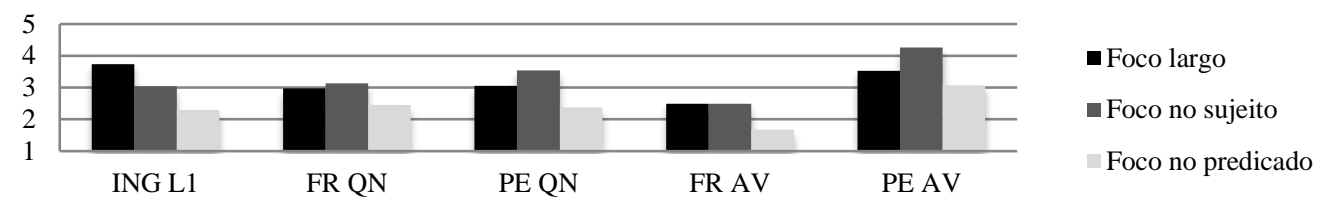

Figura 9. Média de aceitação de construções com there na tarefa de juízos de aceitabilidade por tipo de contexto discursivo (escala 1-5)

Quando consideramos os resultados individuais da tarefa de juízos de aceitabilidade, torna-se claro que, ao contrário do que a figura 9 sugere, os grupos de falantes de L2 não exibiram opcionalidade apenas em relação a alguns contextos. Como ilustrado na figura 10, em todos estes grupos, houve uma elevada percentagem de participantes $(>50 \%)$ que deu, em mediana, uma pontuação acima ou abaixo de 3 a todas as condições experimentais, o que significa que aceitaram ou rejeitaram a construção com there em todos os contextos discursivos testados. No grupo monolingue, em contraste, só $20 \%$ dos participantes exibiu este padrão de comportamento. Dado que a análise estatística (com modelo misto linear generalizado) confirmou que as diferenças entre o grupo de controlo e cada grupo de L2 são estatisticamente relevantes (FR AV x ING L1: estimativa=2.3671, EP=.8568, $p=.00573$; FR QN x ING L1: estimativa=1.5198, EP=.7196, $p=.0347$; PE AV x ING L1: estimativa=1.9924, EP=.7130, $p=.0052$; PE QN x ING L1: estimativa=1.5686, EP=.8012, $p=.0503$ ), podemos concluir que todos os grupos de L2 apresentaram opcionalidade quanto aos tipos de contextos discursivos compatíveis com a construção com there.

\footnotetext{
${ }^{17}$ Para determinar se um valor de $t$ entre 2.00 e1.50 era marginalmente significativo, estimámos os valores de $p$ a partir da distribuição de $t$ como se segue (Baayen, 2008: 248): $2 *$ (1 - pt(abs(X), Y - Z)). Aqui X é o valor de $t$, Y o número de observações e Z o número de efeitos fixos. Esta fórmula estimou os seguintes valores de $p$, que são marginalmente significativos: (i) PE QN $t=-1.727$ corresponde a $p=0.08652476$; e (ii) FR QN $t=-1.699$ corresponde a $p=0.09105647$.
} 


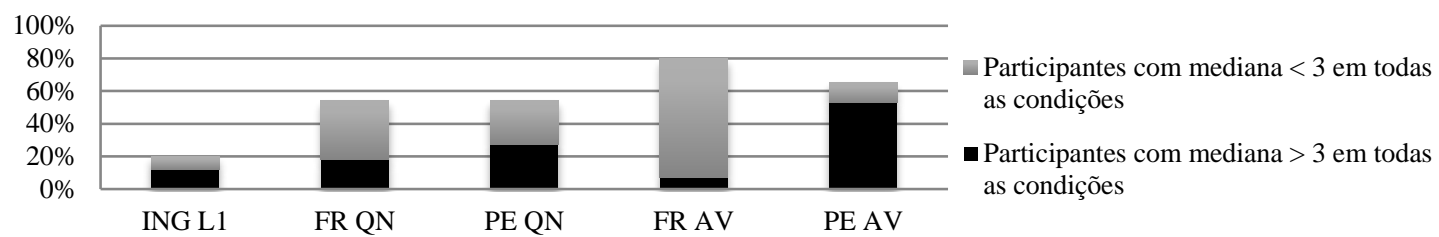

Figura 10. \% de falantes com mediana > ou $<3$ em todas as condições experimentais da tarefa de juízos de aceitabilidade

Em síntese, enquanto os falantes monolingues de inglês foram capazes de distinguir consistentemente as condições em que a inversão com there é possível daquelas em que é impossível ou, pelo menos, desadequada, os falantes de inglês L2 comportaram-se de modo diferente de acordo com o tipo de propriedade em teste. Como é mostrado na tabela 4, as propriedades puramente léxico-sintáticas não geraram problemas no nível quase nativo. Em contraste, as propriedades que envolvem a interface com o discurso, nomeadamente os tipos de verbos intransitivos e contextos discursivos compatíveis com a construção com there, geraram problemas aos falantes de L2, mesmo quando estes se encontravam num nível quase nativo e a sua L1 não diferia da L2 nos aspetos relevantes.

\begin{tabular}{cccccc}
\hline \multirow{2}{*}{ Variável } & \multirow{2}{*}{ Tarefa } & \multicolumn{2}{c}{ Quase nativos } & \multicolumn{2}{c}{ Avançados } \\
& FR L1 & PE L1 & FR L1 & PE L1 \\
\hline \multirow{2}{*}{ Tipo de expletivo } & Drag \& drop & $\mathrm{C}$ & $\mathrm{C}$ & $*$ & $*$ \\
& Juízos de aceitabilidade & $\mathrm{C}$ & $\mathrm{C}$ & $*$ & $*$ \\
\hline \multirow{2}{*}{ Tipo de verbo intransitivo } & Drag \& drop & $\mathrm{C}$ & $*$ & $*$ & $*$ \\
& Priming sintático & $*$ & $*$ & $*$ & $*$ \\
\hline \multirow{2}{*}{ Tipo de contexto discursivo } & Juízos de aceitabilidade & $\mathrm{C}$ & $\mathrm{C}$ & $*$ & $*$ \\
\hline
\end{tabular}

Tabela 4. Resultados de todas as tarefas experimentais

\section{Discussão e conclusão}

Em conjunto, os resultados do presente trabalho apoiam as predições da HI sobre o estádio final da aquisição de L2 nas interfaces, em geral, e da aquisição da construção com there, em particular. Em primeiro lugar, o facto de a distribuição dos sujeitos expletivos it e there ter colocado problemas aos falantes avançados de inglês L2 mas não aos quase nativos indica que, como predito pela HI, esta propriedade léxico-sintática não é um locus de divergência permanente, embora esteja sujeita a atrasos de desenvolvimento significativos. Em segundo lugar, o facto de todos os grupos de falantes avançados e quase nativos de inglês L2 terem exibido opcionalidade relativamente quer aos tipos de verbos que admitem inversão com there, ${ }^{18}$ quer aos tipos de contextos discursivos compatíveis com esta estrutura indica que, tal como predito pela HI (contra a HLI), as propriedades gramaticais que envolvem a interface com o discurso são permanentemente problemáticas em L2, mesmo quando a L1 e a L2 são semelhantes. Em terceiro lugar, o facto de as semelhanças entre L1 e L2 não terem impedido a ocorrência de problemas na interface sintaxe-discurso, combinado com o facto de o desempenho dos grupos de falantes quase nativos ter sido globalmente diferente

\footnotetext{
${ }^{18}$ Recorde-se que, para serem admitidos na construção com there, os verbos, além de terem de ser inacusativos, têm de ser informacionalmente leves (cf. secção 3). Por isso, a distribuição de verbos nesta construção envolve a interface com o discurso.
} 
do do grupo monolingue, sugere que os problemas dos quase nativos não foram, primordialmente, causados por diferenças entre L1 e L2, mas antes por diferenças entre bilinguismo e monolinguismo, tal como predito pela HI (contra a HLI). Finalmente, o facto de todos os grupos de falantes quase nativos terem exibido opcionalidade/indeterminação relativamente a propriedades condicionadas por fatores discursivos nas tarefas mais exigentes em termos de processamento, incluindo os que tiveram um desempenho alvo nas tarefas $d r a g$ \& drop, está em linha com a predição da HI de que a interface sintaxe-discurso é um locus de opcionalidade permanente, porque, mesmo quando os falantes de L2 não têm problemas representacionais, não conseguem ser consistentemente eficientes na integração de informação sintática com informação discursiva em tempo real. Note-se que, como a construção com there com verbos que não be e as suas propriedades sintáticodiscursivas não são tipicamente ensinadas em cursos de inglês, é improvável que os falantes de inglês L2 testados tivessem conhecimento explícito sobre tais propriedades. Por este motivo, é razoável assumir-se que estes falantes recorreram, essencialmente, ao seu conhecimento implícito em todas as tarefas (mesmo nas que não tinham limite de tempo), e que as diferenças de resultados entre tarefas são fruto não do facto de cada uma convocar tipos distintos de conhecimento linguístico, mas antes do facto de cada tarefa colocar diferente peso sobre os recursos de processamento dos falantes.

Apesar de apoiarem a HI, como veremos, os resultados do presente estudo não desmentem totalmente a proposta da HLI de que o input e a L1 influenciam o estado final da aquisição de L2 na interface sintaxediscurso. Dois factos sugerem que estes fatores, realmente, têm um papel na aquisição de propriedades sintático-discursivas em L2 (embora não exatamente o proposto pela HLI). O primeiro é o facto de, na tarefa drag \& drop sobre a variável "tipo de verbo", o grupo de franceses com nível quase nativo em inglês ter tido um desempenho convergente com a L2 e o grupo de portugueses um desempenho divergente. O segundo é o facto de, num estudo anterior com os mesmos grupos de falantes quase nativos (Teixeira, 2017), todos terem tido um desempenho alvo numa tarefa drag \& drop idêntica a esta que tinha como foco uma estrutura de inversão ligeiramente mais frequente em inglês do que a construção com there (Biber et al., 1999: 954-955) a inversão locativa - independentemente de a sua L1 ser ou não diferente da L2. Embora estes factos confirmem a ideia de que a frequência da construção no input e o grau de semelhança entre L1 e L2 têm um papel na aquisição de L2 na interface sintaxe-discurso, os resultados da tarefa de priming sintático administrada no âmbito do presente trabalho comprovam que, ao contrário do que a HLI prediz, estes não são os únicos fatores que determinam se um falante quase nativo consegue ou não ter um desempenho convergente nesta interface. Tal como a HI prediz, os fatores de processamento também têm um papel importante. Em conjunto, estes factos sugerem que a HLI deve pôr de parte a proposta de que os problemas na interface sintaxe-discurso nunca resultam de ineficiências de processamento associadas ao bilinguismo e restringir o seu escopo ao nível de representação linguística. A versão reformulada da HLI poderia ser expressa do seguinte modo: as propriedades que envolvem a interface sintaxe-discurso só criam problemas representacionais persistentes no estádio final de aquisição de L2 quando (i) são muito raras no input e (ii) diferentes na L1 e L2. Note-se que, por apenas se aplicar ao nível de representação linguística, esta versão da HLI, ao contrário da original, é totalmente compatível com a HI. ${ }^{19}$ Crucialmente, só combinando a HI com a versão moderada da HLI conseguimos explicar (i) por que razão, nas tarefas drag \& drop sobre os tipos de verbos compatíveis com a inversão locativa e a construção com there, o desempenho dos falantes quase nativos variou de acordo com a frequência da construção alvo e a distância entre L1 e L2, e (ii) por que razão, no presente trabalho (assim como no estudo sobre inversão locativa), todos os grupos quase nativos exibiram opcionalidade em relação à variável "tipo de verbo", em pelo menos, uma das tarefas exigentes em termos de processamento.

\footnotetext{
${ }^{19}$ Note-se que, na sua forma atual, a HI não prediz que os falantes de L2 são incapazes de desenvolver representações alvo para propriedades sintático-discursivas; prediz antes que, mesmo quando estes não têm qualquer problema representacional na interface sintaxe-discurso, exibem opcionalidade na sua performance, devido a ineficiências de processamento.
} 
A combinação da HI com a HLI só não consegue explicar por que razão, no presente trabalho, os falantes de inglês L2 exibiram mais opcionalidade nas tarefas que se debruçaram sobre a variável "tipo de contexto discursivo" do que nas que tinham como foco os tipos de verbos intransitivos admitidos na construção com there. Recorde-se que, enquanto todos os grupos tiveram problemas nas tarefas drag \& drop e de juízos de aceitabilidade sobre o tipo de contexto discursivo, nas tarefas equivalentes sobre o tipo de verbo, alguns tiveram um desempenho convergente com o dos falantes nativos de inglês, nomeadamente o grupo de portugueses quase nativos (apenas na tarefa de juízos de aceitabilidade) e o grupo de franceses com nível quase nativo em inglês (nas duas tarefas). O facto de este último grupo ter um desempenho convergente na tarefa drag \& drop sobre o tipo de verbo e divergente na tarefa do mesmo tipo sobre contextos discursivos é particularmente intrigante. Afinal, se o input a que o grupo foi exposto foi suficiente para desenvolver representações alvo quanto à distribuição dos verbos na construção com there, porque é que esse input seria insuficiente para promover o desenvolvimento de representações alvo sobre os contextos discursivos em que esta estrutura é adequada, que, além do mais, são os mesmos em que a inversão com il é admitida em francês? À luz deste argumento, propomos que, provavelmente, as diferenças encontradas nas tarefas drag \& drop sobre propriedades sintático-discursivas resultam de fatores de processamento e não de questões representacionais.

É possível que o grau de eficiência dos falantes de L2 na integração de informação sintática com informação discursiva tenha sido influenciado pela quantidade e/ou distância da informação discursiva a ser processada. Note-se que, para decidir se um verbo é ou não discursivamente adequado, o falante tem apenas de ter em conta o seu significado no contexto intrafrásico (e.g., swim 'nadar' é adequado com um sujeito que prototipicamente nade como a goldfish 'um peixinho-dourado', mas não com a student 'um estudante'), enquanto que, para decidir se um contexto discursivo é ou não compatível com a construção com there, necessita de analisar o contexto interfrásico e determinar se, nesse contexto particular, todos os constituintes da frase são parte do foco. Por envolver o processamento de mais informação e de informação mais distante, esta última tarefa, presumivelmente, exige a mobilização de mais recursos cognitivos do que a primeira, o que pode levar a que, neste caso, a carga associada à integração de informação sintática com informação contextual exceda mais frequentemente os recursos cognitivos disponíveis, originando mais ineficiências de processamento e, por conseguinte, mais opcionalidade. Isto pode explicar por que razão, de um modo geral, todos os grupos de falantes quase nativos que testámos tiveram um desempenho pior nas tarefas sobre a variável "contexto discursivo" do que nas tarefas sobre o tipo de verbo.

Em conclusão, os resultados do presente trabalho mostram que o estádio final da aquisição da construção com there em L2 diverge do estádio final da aquisição monolingue desta estrutura, mas esta divergência é seletiva: enquanto as propriedades que envolvem a interface entre sintaxe e discurso são áreas de opcionalidade permanente (independentemente de a L1 ser ou não diferente da L2), as propriedades que envolvem apenas a interface léxico-sintaxe não são problemáticas no estádio final de aquisição de L2, mesmo quando estão sujeitas a atrasos de desenvolvimento substanciais. Estes resultados, por um lado, confirmam a HI e, por outro, infirmam a predição da HLI de que as estruturas na interface sintaxe-discurso só geram problemas quando são infrequentes na L2 e diferentes na L1. O presente estudo sugere, no entanto, que tanto a frequência no input como a distância entre L1 e L2 influenciam a possibilidade de convergência com a L2 a nível representacional do seguinte modo: as propriedades que envolvem a interface sintaxe-discurso criam problemas representacionais persistentes exclusivamente quando são muito raras no input e diferentes na L1 e L2. Naturalmente, quando o falante de L2 tem problemas representacionais relativamente a propriedades na interface sintaxe-discurso, tende a exibir opcionalidade em todos os tipos de tarefas experimentais, incluindo naquelas em que não está sob pressão de tempo. Já quando não tem problemas desta natureza, o falante pode exibir maior ou menor grau de opcionalidade dependendo de certos fatores que influenciam a sua eficiência na integração de informação sintática e discursiva em tempo real, como a quantidade e/ou distância da 
informação discursiva a ser processada (muita informação num contexto interfrásico $\rightarrow$ menos eficiência $\rightarrow$ mais opcionalidade). Os resultados do presente trabalho indicam, assim, que, tal como proposto em Teixeira (2017), a opcionalidade na interface sintaxe-discurso é um fenómeno gradiente. Em certos casos, a opcionalidade é tão residual que só é detetável por tarefas exigentes em termos de processamento, como a tarefa de priming sintático usada neste trabalho. Noutros casos, o grau de opcionalidade é de tal modo elevado que até mesmo uma tarefa experimental offline, sem qualquer limite de tempo, consegue captar este fenómeno. A gradação da opcionalidade na interface sintaxe-discurso explica, assim, um dos principais mistérios da investigação desenvolvida ao longo da última década em aquisição de L2: a razão pela qual os estudos sobre a interface sintaxe-discurso - que se baseiam, na sua maioria, em tarefas offline sem pressão de tempo - têm produzido resultados tão contraditórios. Falta agora determinar exatamente que fatores moderam esta opcionalidade e como interagem. Estas são questões que ficam em aberto para investigação futura.

\section{Referências}

Baayen, H. (2008) Analyzing linguistic data: A practical introduction to statistics using R. Cambridge: Cambridge University Press.

Bader, M., \& Häussler, J. (2010) Toward a model of grammaticality judgments. Journal of Linguistics, 46(2), pp. 273-330.

Belletti, A., Bennati, E., \& Sorace, A. (2007) Theoretical and developmental issues in the syntax of subjects: Evidence from near-native Italian. Natural Language \& Linguistic Theory, 25(4), pp. 657-689.

Belletti, A., \& Bianchi, V. (2016) Definiteness effect and unaccusative subjects: An overview and some new thoughts. In S. Fischer, T. Kupisch, \& E. Rinke (Eds.) Definiteness effects: Bilingual, typological and diachronic variation. Newcastle upon Tyne: Cambridge Scholars Publishing.

Biber, D., Johansson, S., Leech, G., Conrad, S., \& Finegan, E. (1999) Longman grammar of spoken and written English. Londres: Longman.

Bini, M. (1993) La adquisicíon del italiano: Mas allá de las propiedades sintácticas del parámetro pro-drop. In J. Liceras (Ed.), La linguistica y el analisis de los sistemas no nativos (pp. 126-139). Ottawa: Doverhouse.

Bolinger, D. (1977) Meaning and form. Londres: Longman.

Branigan, H. P. (2007) Syntactic priming. Language and Linguistics Compass, 1(2), pp. 1-16.

Breivik, L. E. (1981) On the interpretation of existential there. Language, 57(1), pp. 1-25.

Carlier, A. (2005) L'argument davidsonien: Un critère de distinction entre les prédicats «stage level» et les prédicats «individual level»? Travaux de linguistique, 1(50), pp. 13-35.

Costa, J. (2004) Subject positions and interfaces. The case of European Portuguese. Berlim: Mouton de Gruyter.

Culicover, P., \& Levine, R. D. (2001) Stylistic inversion in English: A reconsideration. Natural Language \& Linguistic Theory, 19(2), pp. 283-310.

Cunnings, I. (2012) An overview of mixed-effects statistical models for second language researchers. Second Language Research, 28(3), pp. 369-382.

Dekydtspotter, L., Sprouse, R., \& Swanson, K. (2001) Reflexes of mental architecture in second-language acquisition: The interpretation of combien extractions in English-French interlanguage. Language Acquisition, 9, pp. 175-227.

Domínguez, L., \& Arche, M. J. (2014) Subject inversion in non-native Spanish. Lingua, 145, pp. 243-265.

Hartmann, J. (2008) Expletives in existentials: English there and German da. (Tese de Doutoramento), Tilburg University, Holanda.

Hopp, H. (2007) Ultimate attainment at the interfaces in second language acquisition: Grammar and processing. (PhD thesis), University of Groningen, Holanda. 
Ivanov, I. P. (2012) L2 acquisition of Bulgarian clitic doubling: A test case for the Interface Hypothesis. Second Language Research, 28(3), pp. 345-368.

Jones, M. A. (1996) Foundations of French syntax. Cambridge/Nova Iorque: Cambridge University Press.

Kato, M., \& Martins, A. M. (2016) European Portuguese and Brazilian Portuguese: An overview on word order. In L. Wetzels, S. Menuzzi, \& J. Costa (Eds.), The handbook of Portuguese linguistics. Hoboken, NJ: Wiley-Blackwell, pp. 15-40.

Kraš, T. (2010) Unaccusativity in L2 Italian at the lexicon-syntax interface. In M. Iverson (Ed.) Proceedings of the 2009 Mind/Context Divide Workshop. Somerville, MA: Cascadilla Proceedings Project, pp. 60-71.

Kraš, T. (2011) Acquiring the syntactic constraints on auxiliary change under restructuring in L2 Italian: Implications for the Interface Hypothesis. Linguistic Approaches to Bilingualism, 1(4), pp. 413-438.

Kuno, S., \& Takami, K. (2004) Functional constraints in grammar: On the unergative-unaccusative distinction. Amsterdão: John Benjamins.

Labelle, M. (1992) Change of state and valency. Journal of Linguistics, 28(2), pp. 375-414.

Levin, B. (1993) English verb classes and alternations: A preliminary investigation. Chicago / Londres: The Chicago University Press.

Levin, B., \& Rappaport Hovav, M. (1995) Unaccusativity at the syntax-lexical semantics interface. Cambridge, MA: MIT Press.

Linck, J., \& Cunnings, I. (2015) The utility and application of mixed-effects models in second language research. Language Learning, 65, pp. 185-207.

Lobo, M., \& Martins, A. M. (2017) Subjects. In A. Dufter \& E. Stark (Eds.) Manual of Romance morphosyntax and syntax. Berlim/Boston: De Gruyter, pp. 27-88.

Lozano, C. (2003) Universal Grammar and focus constraints: The acquisition of pronouns and word order in non-native Spanish. (Tese de Doutoramento), University of Essex, RU.

Lozano, C. (2006) Focus and split-intransitivity: The acquisition of word order alternations in non-native Spanish. Second Language Research, 22(2), pp. 145-187.

Lozano, C. (2008) ¿Déficits de representación o de procesamiento en una segunda lengua? Evidencia de un estudio de resolución de anáfora con griegos adultos aprendices de español. In A. Monroy \& A. Sanchez (Eds.) 25 años de Lingüística Aplicada en España: Hitos y retos / 25 Years of Applied Linguistics in Spain: Milestones and Challenges. Murcia: Editum, pp. 855-866.

Lozano, C., \& Mendikoetxea, A. (2008) Postverbal subjects at the interfaces in Spanish and Italian learners of L2 English: A corpus analysis. In G. Gilquin, S. Papp, \& M. B. Díez-Bedmar (Eds.) Linking up contrastive and corpus learner research. Amsterdão: Rodopi, pp. 85-125.

Lozano, C., \& Mendikoetxea, A. (2010) Interface conditions on postverbal subjects: A corpus study of L2 English Bilingualism: Language and Cognition, 13(04), pp. 475-497.

Lumsden, M. (1988) Existential sentences: Their structure and meaning. Londres: Croom Helm.

Mackenzie, I. (2006) Unaccusative verbs in Romance languages. Hampshire: Palgrave Macmillan.

Margaza, P., \& Bel, A. (2006) Null subjects at the syntax-pragmatics interface: Evidence from Spanish interlanguage of Greek speakers. In M. G. O’Brien, C. Shea, \& J. Archibald (Eds.) Proceedings of GASLA 2006. Somerville, MA: Cascadilla Press, pp. 88-97.

Martins, A. M., \& Costa, J. (2016) Ordem dos constituintes frásicos: Sujeitos invertidos; objetos antepostos. In A. M. Martins \& E. Carrilho (Eds.) Manual de Linguística Portuguesa. Berlim/Boston: De Gruyter, pp. 371-400.

Meisel, J. M. (2008) Child second language acquisition or successive first language acquisition? In B. Haznedar \& E. Gavruseva (Eds.) Current trends in child second language acquisition: A generative perspective. Amsterdão/Philadelphia: John Benjamins, pp. 55-80. 
Mendes, C., \& Iribarren, I. C. (2007) Fixação do parâmetro do sujeito nulo na aquisição do português europeu por hispanofalantes. In M. Lobo \& M. A. Coutinho (Eds.) Textos seleccionados do XXII Encontro Nacional da Associação Portuguesa de Linguística. Lisboa: Associação Portuguesa de Linguística, pp. 483-498.

Mendikoetxea, A. (2006) Unergatives that 'become' unaccusatives in English locative inversion: A lexicalsyntactic approach. In C. Copy \& L. Gournay (Eds.) Points de vue sur l'inversion. Cahiers de recherche en grammaire anglaise de l'énonciation. Paris: Éditions Orphys, pp. 133-155.

Pickering, M. J., \& Ferreira, V. S. (2008) Structural priming: A critical review. Psychological Bulletin, 134(3), pp. 427-459.

Sasse, H.-J. (1987) The thetic/categorical distinction revisited. Linguistics, 25, pp. 511-580.

Schutter, J. S. (2013) An investigation into near-nativeness at the syntax-lexicon interface: Evidence from Dutch learners of English. (Tese de Doutoramento), University of Edinburgh, RU.

Serratrice, L., Sorace, A., Filiaci, F., \& Baldo, M. (2009) Bilingual children's sensitivity to specificity and genericity: Evidence from metalinguistic awareness. Bilingualism: Language and Cognition, 12(2), pp. 239-257.

Sheehan, M. (2007) The EPP and null subjects in Romance. (Tese de Doutoramento), Newcastle University, RU.

Slabakova, R. (2003) Semantic evidence for functional categories in interlanguage grammars. Second Language Research, 19(1), pp. 42-75.

Slabakova, R. (2015) The effect of construction frequency and native transfer on second language knowledge of the syntax-discourse interface. Applied Psycholinguistics, 36(3), pp. 671-699.

Sorace, A. (2006) Gradience and optionality in mature and developing grammars. In G. Fanselow, C. Fery, M. Schlesewsky, \& R. Vogel (Eds.) Gradience in grammars: Generative perspectives. Oxford: Oxford University Press, pp. 106-123.

Sorace, A. (2011a) Cognitive advantages in bilingualism: Is there a 'bilingual paradox'? In P. Valore (Ed.) Multilingualism. Language, power, and knowledge. Pisa: Edistudio, pp. 335-358.

Sorace, A. (2011b) Pinning down the concept of 'interface' in bilingualism. Linguistic Approaches to Bilingualism, 1, pp. 1-33.

Sorace, A. (2012) Pinning down the concept of 'interface' in bilingualism - A reply to peer commentaries. Linguistic Approaches to Bilingualism, 2, pp. 209-216.

Sorace, A. (2016) Referring expressions and executive functions in bilingualism. Linguistic Approaches to Bilingualism, 6(5), pp. 669-684.

Sorace, A., \& Filiaci, F. (2006) Anaphora resolution in near-native speakers of Italian. Second Language Research, 22(3), pp. 339-368.

Sorace, A., \& Serratrice, L. (2009) Internal and external interfaces in bilingual language development: Beyond structural overlap. International Journal of Bilingualism, 13(2), pp. 195-210.

Sorace, A., Serratrice, L., Filiaci, F., \& Baldo, M. (2009) Discourse conditions on subject pronoun realization: Testing the linguistic intuitions of older bilingual children. Lingua, 119(3), pp. 460-477.

Teixeira, J. (2017) Será a interface sintaxe-discurso necessariamente um locus de opcionalidade em L2? O caso da inversão locativa em inglês L2. Revista da Associação Portuguesa de Linguística, 3, pp. 347-386.

Tsimpli, I., \& Sorace, A. (2006) Differentiating interfaces: L2 performance in syntax-semantics and syntaxdiscourse phenomena. In Proceedings of the 30th Annual Boston University Conference on Language Development. Somerville, MA: Cascadilla Press, pp. 653-664.

Tsimpli, I., Sorace, A., Heycock, C., \& Filiaci, F. (2004) First language attrition and syntactic subjects: A study of Greek and Italian near-native speakers of English. International Journal of Bilingualism, 8(3), pp. $257-277$. 
Ward, G., Birner, B., \& Huddleston, R. (2002) Information packaging. In R. Huddleston \& G. K. Pullum (Eds.) The Cambridge grammar of the English language. Cambridge: Cambridge University Press, pp. 1363-1447.

White, L. (2011) Second language acquisition at the interfaces. Lingua, 121(4), pp. 577-590.

White, L., \& Genesee, F. (1996) How native is near-native? The issue of ultimate attainment in adult second language acquisition. Second Language Research, 12(3), pp. 233-265.

Zubizarreta, M. L., \& Nava, E. (2011) Encoding discourse-based meaning: Prosody vs. syntax. Implications for second language acquisition. Lingua, 121(4), pp. 652-669. 